\title{
REYNOLDS NUMBER AND COWL POSITION EFFECTS FOR A GENERIC SIDEWALL COMPRESSION SCRAMJET INLET AT MACH 10: A COMPUTATIONAL AND EXPERIMENTAL INVESTIGATION
}

\author{
by \\ Scott D. Holland* \\ NASA Langley Research Center \\ Hampton, VA 23665
}

\begin{abstract}
$\underline{\text { Abstract }}$
Reynolds number and cowl position effects on the internal shock structure and the resulting performance of a generic three-dimensional sidewall compression scramjet inlet with a leading edge sweep of 45 degrees at Mach 10 have been examined both computationally and experimentally. Prior to the experiment, a threedimensional Navier-Stokes code was adapted to perform preliminary parametric studies leading to the design of the present configuration. Following this design phase, the code was then utilized as an analysis tool to provide a better understanding of the flow field and the experimental static pressure data for the final experimental configuration. The wind tunnel model possessed 240 static pressure orifices distributed on the forebody plane, sidewalls, and cowl and was tested in the NASA Langley 31 Inch Mach 10 Tunnel.
\end{abstract}

\section{$\underline{\text { Nomenclature }}$}

Cx distance from sidewall leading edge to cowl leading edge

$\mathrm{CR}$ contraction ratio, $\mathrm{W} / \mathrm{g}$

g throat gap

$\mathrm{H}$ height of inlet, 4.0 inches

$\mathrm{M}_{1}$ freestream Mach number

p local static pressure, psia

$\mathrm{p}_{\infty} \quad$ static pressure of freestream, psia

$\mathrm{p}_{\mathrm{t}} \quad$ tunnel stagnation pressure, psia

Re Reynolds number

$\mathrm{T}$ static temperature of freestream, deg. $\mathrm{F}$

$\mathrm{T}_{\mathrm{t}}$ tunnel stagnation temperature, deg. $\mathrm{F}$

Tx distance from baseplate leading edge to inlet throat, inches

\footnotetext{
* Research Engineer, Experimental Hypersonics Branch, Space Systems Division. Member AIAA.

Copyright (C) 1992 by the American Institute of Aeronautics and Astronautics, Inc. No copyright is asserted in the United States under Title 17, U.S. Code. The U.S. Government has a royalty-free license to exercise all rights under the copyright claimed herein for Governmental purposes. All other rights are reserved by the copyright owner.
}

$\mathrm{Tx}^{\prime}$ distance from sidewall leading edge to throat

$\mathrm{W}$ inlet width at the sidewall leading edge, inches

$\mathrm{x}$ axial distance, inches

y lateral distance from inlet plane of symmetry, inches

$\mathrm{z} \quad$ vertical distance from baseplate, inches

$\mathrm{i}, \mathrm{j}, \mathrm{k}$ axial, lateral, and vertical coordinate directions

$\xi \quad$ vertical distance from baseplate, inches

$\delta \quad$ sidewall compression angle, degree

$\Lambda \quad$ leading edge sweep angle, degree

$\zeta \quad$ spillage angle, degree

\section{$\underline{\text { Introduction }}$}

The computational and experimental investigation of a generic three-dimensional sidewall compression scramjet inlet (Figures 1 and 2) at Mach 10 evolved through many phases. An initial inviscid assessment of the internal shock structure (see Ref. 1) demonstrated that the principle effect of aft leading edge sweep was the introduction of a downward component of the flow (i.e., toward the cowl) aft of the internal swept shocks. When the cowl is fully retracted, this downturned flow spills out of the inlet. This spillage (shown three-dimensionally in Figure 3) is important in helping the inlet start at lower Mach numbers. Further, the shock induced spillage also provides a variable geometry quality to the fixed geometry inlet in that, as the Mach number is increased, the area (in the plane of the cowl) behind the shock sheets is decreased, since the shocks lie closer to the sidewalls (Figure 4). This reduces the spillage (and increases the mass capture) by partially closing the spillage window, making the inlet more efficient at higher Mach numbers. It is these characteristics which make it attractive to consider a fixed geometry inlet for use over a wide Mach number range. A full discussion of the modification to inviscid two-dimensional oblique shock theory to accommodate the three-dimensional effects of leading edge sweep is presented in Ref. 1.

A preliminary computational parametric study was then performed to identify inlet characteristics pertinent to the optimization of the configuration. The primary interest was in the variation of the performance parameters of mass capture, throat Mach number, total pressure recovery (and hence kinetic energy efficiency), and internal compression with leading edge sweep for adiabatic and cold wall thermal boundary conditions and for laminar and turbulent inflow boundary layers. The results of the trade study which led to 
the selection of a $45^{\circ}$ leading edge sweep configuration were presented in Ref. 2 .

The experimental portion of the work required the coupling of the optimized configuration to the physical limitations of the facility. It was desirable to make the model as large as possible for several reasons: to maximize the length Reynolds number and inflow boundary layer thickness and to increase the instrumentation density on the model. When the cross-sectional area of the model becomes large relative to the inviscid core size of the facility, the effects of wind tunnel blockage must be assessed. Since the proposed wind tunnel model had a maximum cross-sectional area which was $31 \%$ of the inviscid core size of the tunnel (see Figure 5), an inexpensive pressure model with limited instrumentation (referred to as the blockage model) was fabricated and tested. No evidence of tunnel blockage was noted, based on pitot pressure measurements of the freestream and static pressure measurements along the tunnel sidewall (Ref. 3).

With the configuration (and its sizing relative to the facility) established, CFD was employed for the experimental configuration to provide a detailed examination and comparison of the internal flow characteristics with the results from the highly instrumented experimental model. One advantage of CFD is that it provides flow field data in addition to the surface properties. White, Drummond, and Kumar (Ref. 4) point out the utility of CFD for providing parametric studies in a timely and cost effective manner, and once wind tunnel data is obtained, to aid in the explanation of unusual or unexpected phenomena by giving detailed flow field data. Additionally, the code's ability to match the surface measurements obtained experimentally gives the designer greater confidence in the computed flow field data. The direct comparison between computation and experiment was presented in Ref. 5, thereby demonstrating how the two tools may be used to complement one another in an inlet study. Although the scope of the entire project was broader, the present discussion will summarize and highlight the Reynolds number and cowl position effects.

\section{Code Description}

The three-dimensional Reynolds-averaged NavierStokes code of Ref. 6 (SCRAMIN) was adapted for the present study because it uses a well-known and well-proven numerical scheme and has shown favorable comparison with experiment at lower Mach numbers (2 to 6 , which, as a result of this study, is extended to 10). The code solves the three-dimensional Navier-Stokes equations in full conservation form using MacCormack's time-asymptotic, explicit, predictor-corrector method (Ref. 7). This method is second order accurate in time and space and yields to a high degree of vectorization. The present work makes use of an algebraic grid generation technique with linear connecting functions, described in Ref. 8, to obtain the Jacobian and metric data. In order to cluster the grid points near the boundaries in the physical domain, the grid refinement function of Ref. 9 is included in the transformation for the $y$ and $\mathrm{z}$ coordinates.

\section{Computational Grid}

The computational grid for the experimental inlet configuration is presented in Figure 6. (It should be noted that the lateral scale in this figure has been exaggerated by a factor of 2 in order to more clearly view the mesh.) The mesh has 86 grid points in the axial direction, 31 laterally, and 61 vertically (46 inside the inlet and 15 underneath --not shown-- for the flow spillage). The grid is swept at the leading edge sweep angle to better resolve interactions which occur in planes of constant leading edge sweep. The sidewall leading edge is located at $i=30$ and mounts to the forebody plane (baseplate) 9 inches aft of the baseplate leading edge. The throat begins at $i=55$ (9.5 inches aft of the sidewall leading edge); the shoulder is also swept at the leading edge sweep angle. The inlet exit (combustor entrance) is a vertical plane located at $i=72,25$ inches aft of the baseplate leading edge. As indicated in the figure, the inlet throat is longer near the baseplate than at the cowl plane due to the difference in sweep of the throat entrance and exit. In order to accommodate the swept throat entrance and vertical exit, the grid is linearly transitioned from swept to vertical in this region. The aft expansion added to the wind tunnel model to minimize tunnel blockage and to accommodate the rake mechanism was also modeled in the $\mathrm{i}=72$ to 86 region. The entire model was 30 inches long.

\section{Boundary and Initial Conditions}

Since shock-boundary layer interactions depend on the size and character of the incoming boundary layer, the inflow boundary was maintained at freestream conditions and a laminar boundary layer was allowed to develop naturally on the 9 inches of flat plate ahead of the entrance plane of the inlet. An extrapolation boundary condition was applied at the exit plane. On solid surfaces, all velocity components as well as the normal pressure gradient are required to vanish. A constant temperature distribution $(300 \mathrm{~K})$ provided the thermal boundary condition. Open boundaries were calculated assuming vanishing normal gradients in velocity, temperature, and pressure. Since the flow field was symmetric, only half of the field was computed and symmetry boundary conditions were imposed. The initial conditions were given by assigning freestream conditions to each grid point except at the boundaries, where appropriate boundary conditions were applied.

\section{Inflow Boundary Layer}

For $\mathrm{Re}=2.15$ million/ft, the laminar boundary layer thickness (based on $\mathrm{u}=0.995 \mathrm{Ue}$ ) at the inlet entrance station was computed to be $\delta=0.35$ inch. The displacement thickness was computed to be $\delta^{*}=0.20 \mathrm{inch}$, and the inlet inflow momentum thickness was $\theta=0.0076$ inch. The Reynolds number based on momentum thickness was $\operatorname{Re}_{\theta}=1361.6$. For $\operatorname{Re}=0.55 \mathrm{million} / \mathrm{ft}$, the laminar boundary layer thickness was found to be $\delta=0.60$ inch. The displacement thickness was computed to be $\delta *=0.32$ inch, 
and the inlet inflow momentum thickness was $\theta=0.0130$ inch. The Reynolds number based on momentum thickness was $\operatorname{Re}_{\theta}=595.83$. Tauber (Ref. 10) presented empirical correlations of transition measurements. The equation $\operatorname{Re}_{\theta} / M_{\text {edge }}=$ constant was found to be an approximate correlation for a supersonic or hypersonic boundary transition criterion, where the constant varies between 150 and 350 depending upon the ratio of roughness height to momentum thickness among other parameters. For the Mach 10 inflow, the high and low Reynolds number test conditions yield values of $\mathrm{Re}_{\theta} / \mathrm{M}_{\text {edge }}$ of 136 and 60 , respectively, each of which is less than the value for transition.

\section{Model Description}

Generic, three-dimensional sidewall compression inlet configurations such as considered in the present work have been under study for several years. Northam and Anderson (Ref. 11) trace the development of scramjet research at NASA Langley. Much of the work on this type of inlet has been performed by Trexler (Refs. 12-16), and his notation will be used in the present study. A sketch of the inlet model is given in Figure 1. The leading edge sweep was fixed at 45 degrees as a result of the computational parametric study (Ref. 17). This configuration also demonstrated acceptable performance based on data obtained from the wind tunnel blockage test (Ref. 3). In these tests, no wind tunnel blockage was observed and the inlet appeared to start for all cowl position, Reynolds number, contraction ratio, and angle of attack combinations tested. As a result of a trade study (Ref. 13), the sidewall compression angle was fixed at 6 degrees, a compromise between larger compression angles leading to stronger internal shocks and increased risk of boundary layer separation and smaller compression angles leading to weaker internal shocks but requiring the inlet be longer to obtain the same contraction ratio, imposing a size and weight penalty on the inlet. The models were injected into the tunnel in flight orientation, with the cowl on bottom. The forebody plane was represented by a flat plate.

The contraction ratio is defined as the ratio of the entrance area to the throat area, but since the inlet height was constant (i.e., no compression in the forebody plane), this reduced to the ratio of the inlet entrance width to the throat gap, W/g (see Figure 1). The contraction ratio could be varied between the runs by laterally moving one of the sidewalls. Thus there was an effective centerline for each of the three contraction ratios. Static pressure orifices were oriented such that effective centerline pressure distributions could be obtained for each contraction ratio. Lateral arrays of pressure orifices provided the horizontal pressure distribution at 25 axial stations ranging from the leading edge of the baseplate throughout the inlet (Figure 7). Since shock interactions and impingements occurred along lines of constant sweep, vertical arrays of orifices on the sidewalls were swept at the leading edge sweep angle (Figure 8). The centerline of the cowl was also instrumented with 15 static pressure orifices.

The cowl position was defined by the forward extent of the cowl leading edge ahead of the throat $\left(\mathrm{Cx}^{\prime}\right.$, see Figure 8$)$ as a percentage of the distance to the throat $\left(\mathrm{Tx}^{\prime}\right)$. Thus, when the cowl was moved forward halfway between the beginning of the throat and the sidewall leading edge, it was termed 50\% Cowl $\left(\mathrm{Cx}^{\prime} / \mathrm{Tx}^{\prime}=0.50\right)$. Likewise, when the cowl was forward of the throat by one quarter of the distance between the throat and sidewall leading edge, it was termed $25 \%$ Cowl $\left(\mathrm{Cx}^{\prime} / \mathrm{Tx}^{\prime}=0.25\right)$. Finally, when the cowl was located at the throat, it was termed $0 \% \operatorname{Cowl}\left(\mathrm{Cx}^{\prime} / \mathrm{Tx}^{\prime}=0.00\right)$.

The inlet sidewalls were 4.0 inches tall with a total length of 21 inches. The sidewalls were mounted on a 30 inch long flat plate (referred to as the baseplate) which provided the inflow laminar boundary layer. The entire model was manufactured of OFHC copper to allow for rapid conduction of heat away from the sharp leading edges. This preserved the integrity of the surfaces while helping to maintain a nearly uniform temperature distribution over the entire model. Pitot probes at the same axial location as the baseplate leading edge (in connection with settling chamber pressure and temperature) provided tunnel flow conditions. A photograph of the inlet model is presented in Figure 2. The large enclosure opposite the sidewalls (top of figure) housed the pressure modules and was known as the ESP bay.

\section{Facility/Test Technique Description}

Tests were performed in the 31-Inch Mach 10 Tunnel located at the NASA Langley Research Center. Formerly known as the Continuous Flow Hypersonic Tunnel, this facility was originally designed to run in a blowdown start, continuous flow mode. Due to energy conservation measures, the facility has operated in the blowdown mode only since the mid-1970's. The test gas, dry air, is heated to a nominal temperature of $1850^{\circ} \mathrm{R}$ to prevent air liquefaction in the 31 - by 31 -inch square test section. The maximum reservoir pressure is approximately 1500 psia. The 31-Inch Mach 10 Tunnel is the only hypersonic facility in the USA to have a three-dimensional contoured nozzle; Beckwith and Miller (Ref. 18) point out that, due to its three-dimensional contoured design, the Mach 10 nozzle is free of the centerline disturbance characteristically observed in axisymmetric contoured nozzles. Primarily due to this highly uniform core flow, Miller (Ref. 19) identified this facility as particularly attractive for CFD computer code calibration studies.

The model is supported on a hydraulically operated, sidewall mounted injection system capable of injecting the model to centerline in less than 0.6 second. Prior to injection, the model is stored in a housing which is isolated from the test section by a sliding door. This housing rotates about a vertical axis to provide access to the model but blocks the optical path; therefore, conventional schlieren photography is not available. This sidewall mounted 
rotating arrangement allows access to the model without opening the test section to atmosphere; hence, model changes could be made easily without having to shut down the tunnel when it was operated in continuous mode (as shown in Figure 9). Typically the pitot pressure of the tunnel is not obtained during the run due to the orientation of the injection system and location of the model in the facility. Freestream conditions are therefore computed based on measured values of reservoir pressure $\mathrm{p}_{\mathrm{t} 1}$ and temperature $\mathrm{T}_{\mathrm{t} 1}$ using an isentropic expansion accounting for imperfectgas effects in the reservoir. The present model was equipped with pitot probes to measure the freestream pitot pressure, and the measured pressures agreed with the computed values to within the accuracy of the measurement.

The tunnel is equipped to handle a number of types of instrumentation, including force and moments, surface pressures, and surface heat transfer rates. The pitot pressures and surface pressures were measured by an electronically scanned pressure (ESP) system (ESP-32 model 780, manufactured by Pressure Systems, Incorporated (PSI)). The ESP modules each contain 32 piezo-resistance sensors and were located inside a bay inside the model to minimize the tubing length and hence settling (lag) time. In order to maintain the ESP modules at constant temperature, atmospheric air was bled in to the ESP bay. Thermocouples placed in the bay and on each module indicated that the temperature varied by no more than 1 degree $\mathrm{F}$ during the run. (It was discovered quite by accident that similar results were obtained when the bleed air was not introduced into the ESP bay. With short run times (e.g., approximately 10 seconds), there was sufficient lag to prevent any heating of the ESP bay until several seconds after the run.) A pneumatically controlled slide allows the transducers to be calibrated on-line. This on-line calibration consists of applying three known pressures (vacuum levels), chosen to span the range of the expected measured pressures. In anticipation of the widely differing pressure ranges on the model, the pressure orifices were connected to modules rated for either $0.36 \mathrm{psi}, 2.5 \mathrm{psi}$, or $5.0 \mathrm{psi}$.

\section{Pressure Measurement Uncertainty}

Manufacturer specifications indicate that the overall system uncertainty was $0.07 \%$ full scale. Thus the largest error was obtained when measuring the lowest pressures. For example, $0.07 \%$ full scale for a 0.36 psi module corresponds to an uncertainty of 0.00025 psi. When measuring pressures in the vicinity of freestream static (0.03psi for $\mathrm{Re}=2.15 \mathrm{million} / \mathrm{ft}$ ), this amounts to a relative uncertainty of $0.84 \%$. At the lowest Reynolds number $(0.55 \mathrm{million} / \mathrm{ft})$, the freestream static pressure is approximately $0.009 \mathrm{psi}$, so that at that level, the relative uncertainty would be $2.8 \%$. For the 2.5 psi module, a $0.07 \%$ full scale uncertainty corresponds to 0.00175 psi. Ideally this range would be used to measure pressures no lower than the maximum of the next lowest range pressure model (0.36 psi). In this case, the relative uncertainty is $0.5 \%$. In order to prevent the 0.36 psi modules from being overscaled, orifices where the maximum anticipated pressure for any given configuration in the test matrix exceeded 0.3 psi were connected to the 2.5 psi module. This led to a few instances where for some configurations, the 2.5 psi module was used to measure pressures below 0.36 psi. For the $\mathrm{Re}=2.15 \mathrm{million} / \mathrm{ft}$ runs, the lowest measured pressure for this range module was $0.13 \mathrm{psi}$, and the corresponding relative uncertainty was $1.3 \%$. For the $\mathrm{Re}=0.55 \mathrm{million} / \mathrm{ft}$ runs, the minimum pressure fell to approximately $0.07 \mathrm{psi}$, representing a relative uncertainty of $2.5 \%$. The 5.0 psi modules were used strictly for pitot measurements, for which the worst case relative uncertainty was $0.35 \%$. Thus for the high Reynolds number runs, the worst case relative uncertainty in the pressure measurements was $1.3 \%$, and for the low Reynolds number runs, $2.8 \%$. Run to run repeatability was found to be approximately $1 \%$.

\section{$\underline{\text { Results }}$}

\section{Reynolds Number Effects}

Decreasing the Reynolds number indicates by definition that the viscous forces take on greater significance with respect to the momentum forces. Hence, boundary layer thicknesses are expected to increase and, more importantly to the inviscid flow field, the displacement thicknesses increase, causing all surfaces to possess effectively larger wedge angles. This in turn causes the sidewalls to generate stronger shocks and increases the internal compression of the inlet. Beyond the displacement effects, an increased boundary layer thickness influences the shock impingements and reflections and may increase the likelihood of flow separation. The present work examines the effects of a factor of four increase in Reynolds number.

The Reynolds number effects for the $\mathrm{CR}=3,0 \%$ cowl configuration are demonstrated in Figures 10 and 11. The axial baseplate centerline pressure $\left(\mathrm{p} / \mathrm{p}_{\infty}\right)$ distributions for $\mathrm{Re}=2.15,1.14$, and $0.55 \mathrm{million} / \mathrm{ft}$ indicate that this relatively small range of Reynolds number has a significant impact on the flow structure (and hence pressure distribution). The viscous interaction is observed at the leading edge of the baseplate, that is, $\mathrm{p} / \mathrm{p}_{\infty}$ decreases monotonically from the leading edge. Additionally, the baseplate pressure is observed to increase due to the increased boundary layer growth with decreased Reynolds number. The pressure rise on the baseplate due to the interaction with the sidewall leading edge glancing shocks is observed to move forward with decreasing Reynolds number, located inside the inlet at $\mathrm{x}^{\prime} / \mathrm{Tx}^{\prime}=0.1$ for $\mathrm{Re}=2.15 \mathrm{million} / \mathrm{ft}$ and upstream of the inlet entrance at approximately $\mathrm{x}^{\prime} / \mathrm{Tx}^{\prime}=-0.2$ for the lower Reynolds numbers. Flow separation ahead of the inlet is observed in the spanwise pressure distribution at $\mathrm{x}^{\prime} / \mathrm{Tx}^{\prime}=-0.1052$ (Figure 11) at the lower Reynolds number. At $\mathrm{Re}=2.15 \mathrm{million} / \mathrm{ft}$, the pressure distribution is laterally uniform; however, at $\mathrm{Re}=1.14$ and $0.55 \mathrm{million} / \mathrm{ft}$, the pressure is not only higher than at $\mathrm{x}^{\prime} / \mathrm{Tx}^{\prime}=-0.52$ (the next upstream station), but it demonstrates a significant pressure relief as the flow spills around the outside of the inlet 
sidewalls. (This lateral pressure relief is also demonstrated in the oil flows; see Figure 19 of Ref. 20.)

The sidewall centerline axial pressure distribution is given in Figure 12. Again, an overall increase in compression is noted, primarily by way of increased compressive turning due to the increased displacement thickness with decreased Reynolds number. The forward progression of the sidewall shock impingement is particularly evident. At $\mathrm{Re}=2.15 \mathrm{million} / \mathrm{ft}$, the pressures climb to a plateau at $x^{\prime} / T x^{\prime}=1.2$. The peak moves forward to approximately $\mathrm{x}^{\prime} / \mathrm{Tx}^{\prime}=1.06$ for $\mathrm{Re}=1.14 \mathrm{million} / \mathrm{ft}$ and to $\mathrm{x}^{\prime} / \mathrm{Tx} \mathrm{x}^{\prime}=0.96$ at $\mathrm{Re}=0.55 \mathrm{million} / \mathrm{ft}$.

Figure 13 shows a comparison of sidewall and baseplate pressure contours obtained from computation and experiment for the $\mathrm{CR}=3$ configuration at $\mathrm{Re}=2.15$ and 0.55 million/ft. Among the noteworthy interactions demonstrated in the figure are the strong pressure rise and relaxation (viscous interactions) near the sidewall leading edge, the sidewall shock impingement, the expansion of the flow around the shoulder (particularly evident on the baseplate aft of the shoulder), and the cowl shock. Inviscid shock locations are given as dashed lines in the figure for comparison. The salient features of the complex interactions are captured by the computation. Sidewall pressure contours indicate a forward movement of the shock impingement from aft of to slightly upstream of the throat entrance with decreasing Reynolds number. On the sidewall, both the location and magnitude of the computed pressure rises associated with the interactions are in agreement with the experimental values. However on the baseplate, it is observed that the forward pressure rise is underpredicted by the computation. It was experimentally observed that a separation due to the glancing shocks led to a forward pressure rise which increased dramatically in size and magnitude with increasing contraction ratio.

\section{Cowl Position Effects}

Examination of the baseplate centerline pressure distribution for the contraction ratio of 3 configuration at $\mathrm{Re}=2.15 \mathrm{million} / \mathrm{ft}$ (Figure 14) indicates that there exists a slight increase in centerline pressure distribution as a result of the forward placement of the cowl. Due to a more sensitive scale, this is better observed in the pressure distributions along lateral arrays upstream of the sidewall leading edge (e.g., Figure 15). It is noted that upstream of the sidewall leading edge $\left(\mathrm{x}^{\prime} / \mathrm{Tx}^{\prime}=-0.1052\right)$, the forward cowl position causes an increase in the magnitude of the (nominally uniform) lateral pressure distribution. (The effect appears to be diminished with increasing distance inside the inlet from the leading edge -- see Ref. 5.) Since the effect is small, the overall increase in magnitude of the axial baseplate pressure distribution diminishes the relative significance of the effect, as a $\Delta(\mathrm{P} / \mathrm{Pinf})=0.1$ represents a $10 \%$ increase in $\mathrm{P} / \mathrm{Pinf}$ at 1.0 but only a $2 \%$ increase at $\mathrm{P} / \mathrm{Pinf}=5$.

The axial cowl centerline pressures are shown in Figure 16. It is apparent that the pressures for the three cowl positions appear to overlap each other, indicating that the pressure distribution on the cowl is driven primarily by the internal glancing shock locations. It was demonstrated computationally (Ref. 5) that a major constituent of the sidewall/baseplate corner flow was induced crossflow, and that, when the sidewalls were sufficiently far apart, the crossflow was damped before interacting at the centerline. A similar induced crossflow is initiated at the cowl, and due to the proximity of the sidewalls at the throat, the crossflow reaches the centerline near the cowl leading edge, forming recirculation regions which dominate the span. This crossflow is enhanced by the downturning imparted by the glancing shocks to both the core flow and the sidewall boundary layer. The axial pressure distribution on the sidewall centerline (Figure 17) indicates that the effects of the cowl are very small relative to the magnitude of the pressure.

Cowl position effects for $\mathrm{Re}=2.15,1.14$, and 0.55 million/ft were examined in Ref. 5, and it was found that the baseplate pressure differential among the three cowl positions is increased with decreased Reynolds number. At a Reynolds number of 0.55 million $/ \mathrm{ft}$, the differential in noted much farther into the inlet than for the high Reynolds number. For example, the lateral pressure distributions on the baseplate for the three cowl positions collapse to approximately the same pressure at $\mathrm{x}^{\prime} / \mathrm{Tx}^{\prime}=0.42$ at $\mathrm{Re}=2.15 \mathrm{million} / \mathrm{ft}$, at $\mathrm{x}^{\prime} / \mathrm{Tx}^{\prime}=1.0$ for $\mathrm{Re}=1.14 \mathrm{million} / \mathrm{ft}$, and the pressures never seem to come to the same level for the $\mathrm{Re}=0.55 \mathrm{million} / \mathrm{ft}$. Since the boundary layer thickness increases with decreased Reynolds number, the disturbance from the cowl is best able to transmit through the thicker boundary layer associated with the lowest Reynolds number. It was also noted that the increase in baseplate pressure due to the cowl position was not found at the higher contraction ratios. Since the higher contraction ratios were observed to form a separation on the baseplate which fed significantly forward of the inlet entrance, it is clear that the increase due to the cowl position is second order compared to the pressure increase due to the separation. On the sidewall near the cowl, the cowl position was still observed to have the effect of increased local compression for the cowl forward positions, but these regions are typically limited to the lower half of the sidewall.

\section{Summary of Computed Inlet Performance Parameters}

A summary of the Reynolds number and cowl position effects on mass capture, throat Mach number, total pressure recovery, $\mathrm{Pt} 2 / \mathrm{Pinf}$, and inlet compression is given in Table 1. The Reynolds number effects on inlet mass capture are significant. It is noted that the movement of the sidewall shock impingement forward of the inlet throat (forward of the cowl leading edge) has led to a $3 \%$ decrease in the mass capture of the inlet. It was previously noted that the swept glancing shocks induce a downward component to the flow which leads to flow spillage ahead of the cowl. Strong downturning in the sidewall boundary layer at the swept shock impingement has also been noted. When this 
impingement occurs aft of the cowl leading edge, the flow along the sidewall which is turned downward at the impingement is captured by the inlet. However, when this impingement is moved forward of the cowl leading edge (as with the decreased Reynolds number), an additional spillage increment is noted. The decrease in total pressure recovery (and hence kinetic energy efficiency), throat Mach number, and the increase in average compression all indicate that the decrease in Reynolds number leads to an increase in internal shock strength.

The forward placement of the cowl is also observed to have a large influence on the mass capture of the inlet, since more of the downturned flow is prevented from spilling. The shock formed on the leading edge of the cowl is noted to produce an overall decrease in the average throat Mach number and total pressure recovery while increasing the average compression of the inlet exit plane.

\section{Conclusions}

A model of a generic, sidewall compression scramjet inlet with a leading edge sweep of 45 degrees has been tested in the NASA Langley 31 Inch Mach 10 Tunnel. CFD was employed both early in the project to aid in the design process and concurrently with the experimental work to provide a detailed examination and comparison of the internal flow characteristics with experiment. From a broad based study involving the effects of contraction ratio, cowl position, and Reynolds number using a variety of testing techniques, the present work summarizes and highlights the Reynolds number and cowl position effects on the internal pressure distribution.

A forward cowl position was observed to increase the baseplate pressure distribution; this increase was also noted upstream of the inlet. When the Reynolds number was decreased, significant separation regions forward of the inlet entrance obscured the incremental increase in pressure caused by a forward cowl position.

The principle effect of a decrease in Reynolds number was a forward movement in the sidewall shock impingement lines due to the increased displacement of the sidewall boundary layers. A slight increase in pressure was also noted. For the $0 \%$ cowl (i.e., cowl located at the throat), a $3 \%$ decrease in mass capture was noted due to the placement of the sidewall shock impingement forward of the cowl leading edge. A decrease in Reynolds number also led to a separation on the baseplate evident upstream of the inlet entrance by way of a dome shaped lateral pressure distribution, indicating pressure relief as the separated flow spilled around the outside of the sidewalls. Significant changes in internal shock structure are observed over a Reynolds number range spanning a factor of four. This sensitivity to Reynolds number illustrates the challenges of attempting to extrapolate ground based test data to flight and supports the use of CFD to form that bridge.

\section{$\underline{\text { Acknowledgements }}$}

The author gratefully acknowledges Jeff Hodge and Sheila Wright (NASA Langley) for technical assistance in the operation of the wind tunnel and data acquisition system.

This work was supported in part by NASA/ONR/AFOSR Grant NAGW-1072 while the author was a doctoral candidate at North Carolina State University.

\section{$\underline{\text { References }}$}

1. Holland, Scott D. and Perkins, John N.: Internal Shock Interactions in Propulsion/Airframe Integrated ThreeDimensional Sidewall Compression Scramjet Inlets. 28th AIAA/ASME/SAE/ASEE Joint Propulsion Conference, July 6-8, 1992, Nashville, TN, AIAA-923099.

2. Holland, Scott D. and Perkins, John N.: A Computational Parametric Study of Three-Dimensional Sidewall Compression Scramjet Inlets at Mach 10. 26th AIAA/ASME/SAE/ASEE Joint Propulsion Conference, July 16-18, 1990, Orlando, FL, AIAA-902131.

3. Holland, S. D., Hodge, J. S., and Perkins, J. N.: Wind Tunnel Blockage Study of a Generic Three-Dimensional Sidewall Compression Scramjet Inlet at Mach 10. AIAA 29th Aerospace Sciences Meeting, January 7-11, 1991, Reno, NV, AIAA-91-0294.

4. White, M. E., Drummond, J. P., and Kumar, A.: Evolution and Application of CFD Techniques for Scramjet Engine Analysis. J. Propulsion, Vol. 3, No. 5, Sept.-Oct. 1987.

5. Holland, Scott D.: A Computational and Experimental Investigation of a Three-Dimensional Hypersonic Scramjet Inlet Flow Field. Ph.D. Dissertation, North Carolina State University, March 1991.

6. Kumar, A.: Numerical Simulation of Scramjet Inlet Flow Fields. NASA-TP-2517, May 1986.

7. MacCormack, R. W.: The Effect of Viscosity in Hypervelocity Impact Cratering. AIAA Hypervelocity Impact Conference, April 30-May 2, 1969, AIAA-69354.

8. Smith, R. E.: Two-Boundary Grid Generation for the Solution of the Three-Dimensional Compressible Navier-Stokes Equations. Ph.D. Dissertation, Old Dominion University, 1981.

9. Roberts, Glyn O.: Computational Meshes for Boundary Layer Problems. Proceedings of the Second International Conference on Numerical Methods in 
Fluid Dynamics, Sept. 15-19, 1970, Lecture Notes in Physics, Vol. 8, edited by Maurice Holt, pp.171-177.

10. Tauber, M. E.: A Brief Review of Some Mechanisms Causing Boundary Layer Transition at High Speeds. NASA-TM-102834, 1990.

11. Northam, G. Burton and Anderson, G. Y.: Supersonic Combustion Ramjet Research at Langley. AIAA 24th Aerospace Sciences Meeting, Jan. 6-9, 1986, Reno, NV, AIAA-86-1744.

12. Trexler, Carl A.: Performance of an Inlet for an Integrated Scramjet Concept. J. Aircraft, Vol. 11, No. 9, September 1974.

13. Trexler, Carl A.: Inlet Performance of the Integrated Langley Scramjet Module (Mach 2.3 to 7.6). AIAA/SAE 11th Propulsion Conference, Sept. 29-Oct. 1, 1975, Anaheim, CA, AIAA-75-1212.

14. Trexler, Carl A. and Souders, Sue W.: Design and Performance at a Local Mach Number of 6 of an Inlet for an Integrated Scramjet Concept. NASA TN D7944, August 1975.

15. Trexler, Carl A.: Inlet Starting Predictions for SidewallCompression Scramjet Inlets. 24th AIAA/SAE/
ASME/ASEE Joint Propulsion Conference, Boston, MA, July 11-13, 1988. AIAA-88-3257.

16. Trexler, Carl A.: Tests of Two Sidewall-Compression Scramjet Inlets at Mach 18.1 to 21.6 in Helium. National Aero-Space Plane Technology Report, Feb. 1988.

17. Holland, Scott D. and Perkins, John N.: A Computational Parametric Study of Three-Dimensional Sidewall Compression Scramjet Inlets at Mach 10. AIAA-90-2131.

18. Beckwith, I. E. and Miller, C. G.: Aerothermodynamics and Transition in High-Speed Wind Tunnels at NASA Langley. Annu. Rev. Fluid Mech. 1990. 22:419-439.

19. Miller, C. G.: Experimental and Predicted Heating Distributions for Biconics at Incidence in Air at Mach 10. NASA-TP-2334, 1984.

20. Holland, Scott D., and Perkins, John N.: Contraction Ratio Effects in a Generic Three-Dimensional Sidewall Compression Scramjet Inlet: A Computational and Experimental Investigation. AIAA 22nd Fluid Dynamics, Plasma Dynamics, and Lasers Conference, June 24-26, 1991, Honolulu, HI, AIAA-91-1708.

Table 1. Summary of Computed Inlet Performance Parameters

\begin{tabular}{|c|c|c|c|c|c|c|c|c|}
\hline \multicolumn{3}{|c|}{$\begin{array}{l}\text { Configuration } \\
\text { CR / Reynolds / Cowl } \\
\text { Number } \\
\end{array}$} & $\begin{array}{c}\eta_{\mathrm{ke}} \\
\%\end{array}$ & $\begin{array}{l}\text { \% Mass } \\
\text { Capture }\end{array}$ & $\begin{array}{l}\text { Mach } \\
\text { Number }\end{array}$ & $\begin{array}{c}\text { Total } \\
\text { Pressure } \\
\text { Recovery }\end{array}$ & $\begin{array}{l}\text { Pt2/ } \\
\text { Pinf }\end{array}$ & $\begin{array}{c}\text { P/ } \\
\text { Pinf }\end{array}$ \\
\hline 3 & $2.15 \times 10^{6} / \mathrm{ft}$ & $0 \%$ & $\overline{99.24}$ & $\bar{~} 93.4$ & $\overline{6.30}$ & 0.609 & $\overline{361.6}$ & $\overline{9.20}$ \\
\hline 3 & $0.55 \times 10^{6} / \mathrm{ft}$ & $0 \%$ & 98.71 & 90.4 & 5.72 & 0.448 & 309.0 & 9.70 \\
\hline 3 & $2.15 \times 10^{6} / \mathrm{ft}$ & $50 \%$ & 98.82 & 98.0 & 5.99 & 0.476 & 353.0 & 9.73 \\
\hline
\end{tabular}

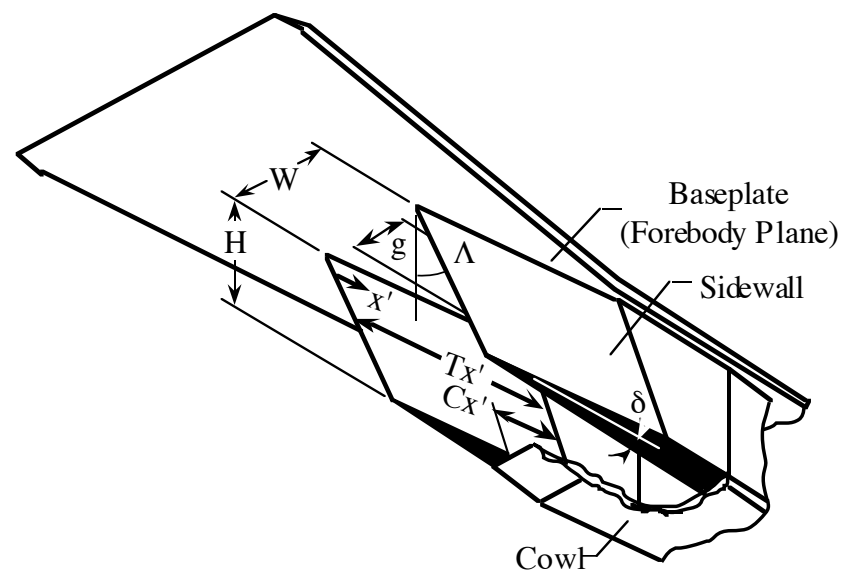

Figure 1: Inlet Model Shown in Flight Orientation 
Paste Photograph Here

(Photo ID: NASA-L-90-04394)

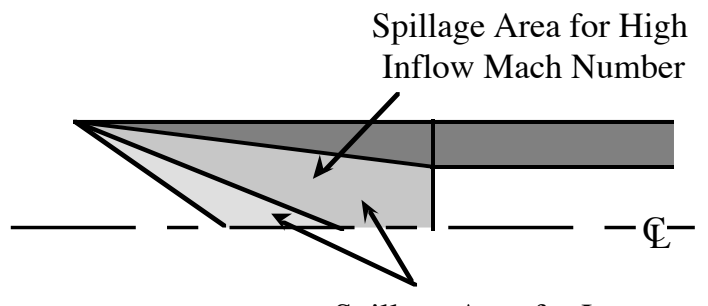

Spillage Area for Low Inflow Mach Number

Figure 4: Spillage Area (in plane of the cowl) for Low and High Inflow Mach Numbers

Figure 2: Photograph of Inlet Model

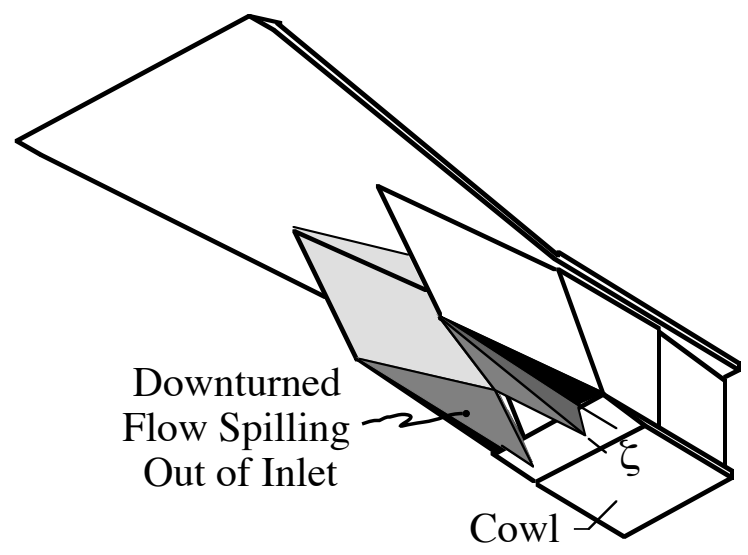

Figure 3: Flow Spillage Due to Swept Shock Sheet Emanating from Sidewall Leading Edge (Spillage Angle $\zeta$ is Exaggerated)

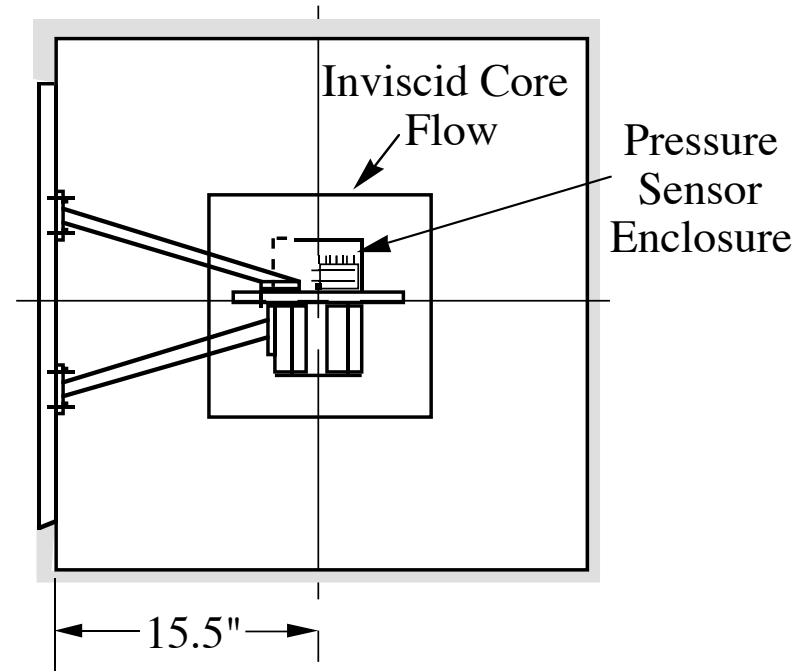

Figure 5: Inlet Injected into Inviscit Core Flow 
Paste wire mesh computational grid here.

Figure 6: Computational Grid of Inlet Sidewall and Baseplate

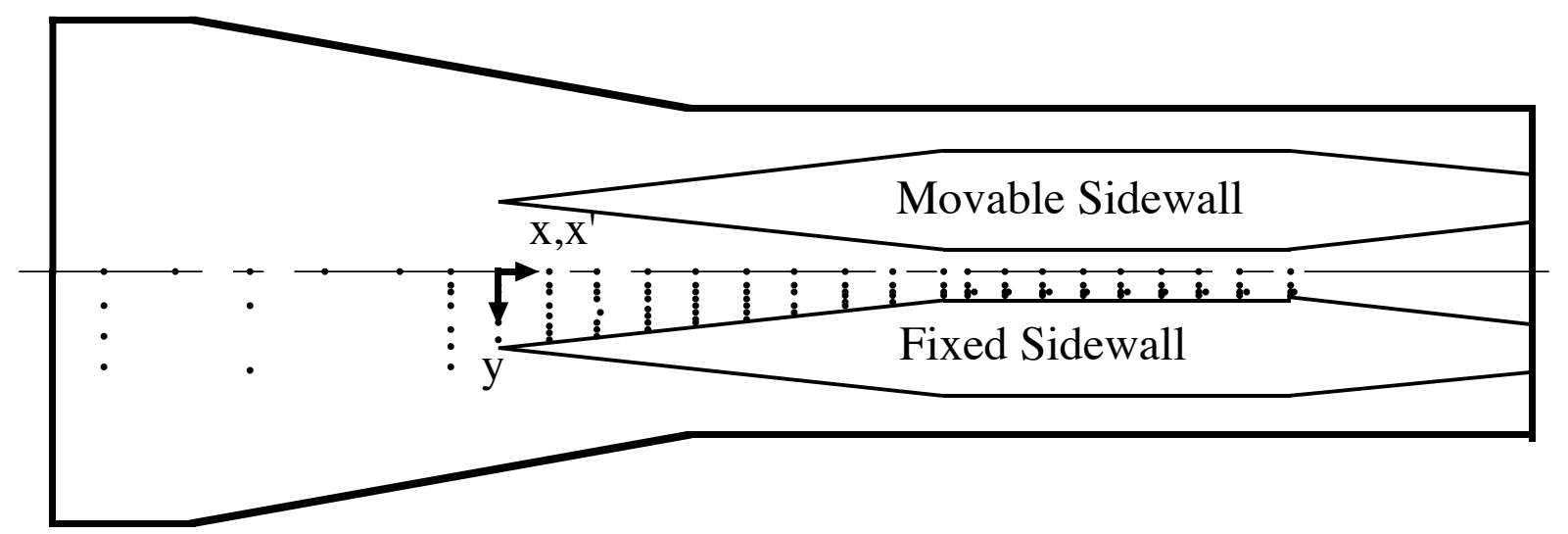

Figure 7: Baseplate Orifice Loacations and Coordinate System Identification (Centerline Shown for $\mathrm{CR}=3$ Configuration)

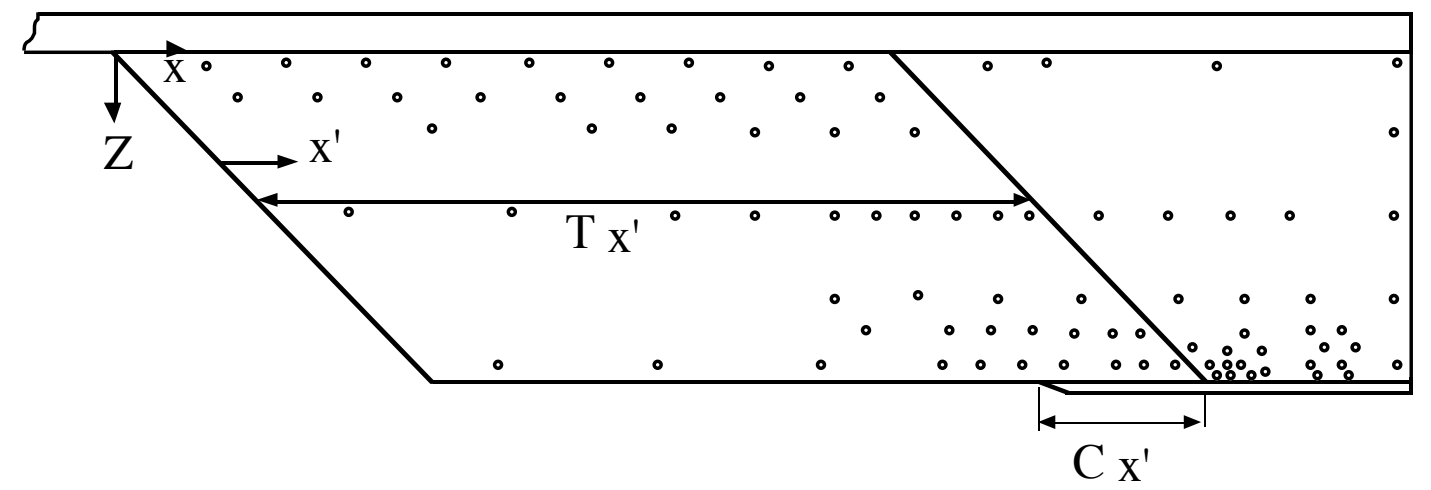

Figure 8: Sidewall Orifice Loacations and Coordinate System Identification 

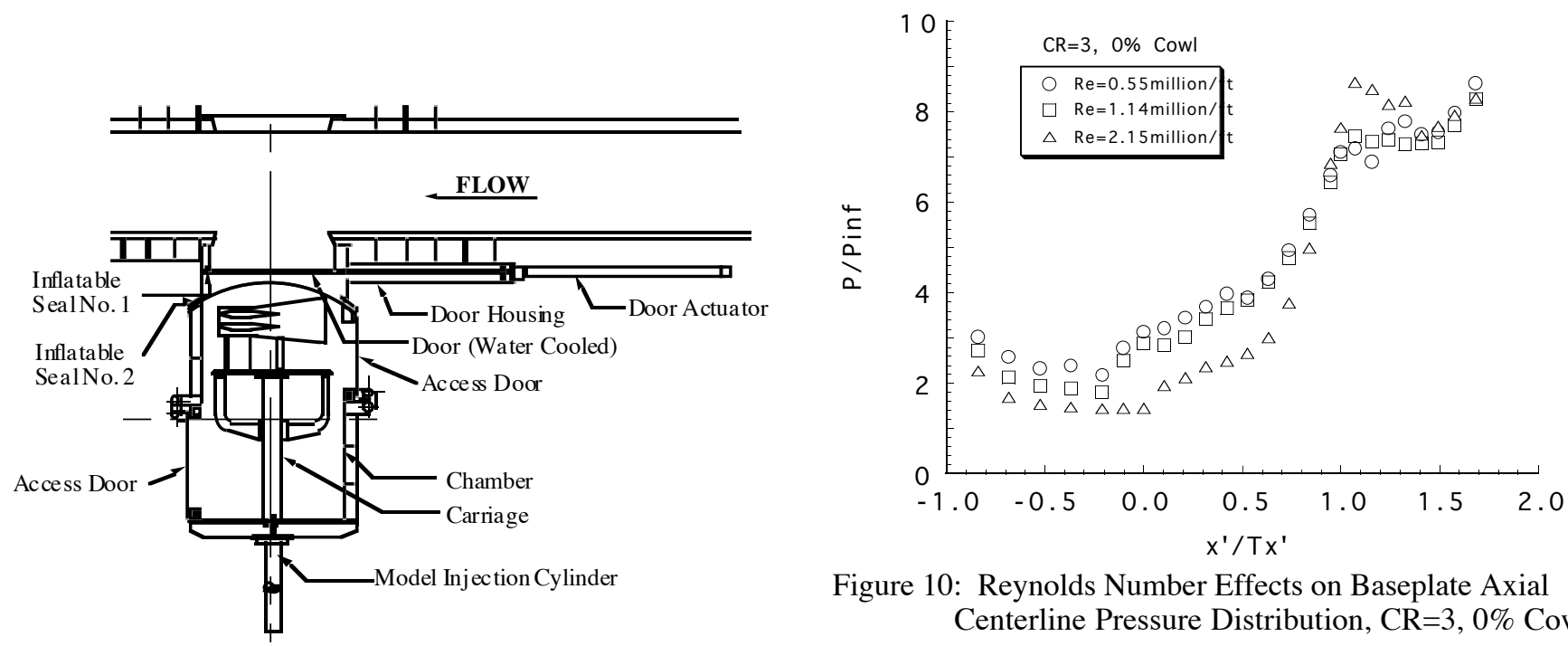

Figure 10: Reynolds Number Effects on Baseplate Axial Centerline Pressure Distribution, $\mathrm{CR}=3,0 \%$ Cowl
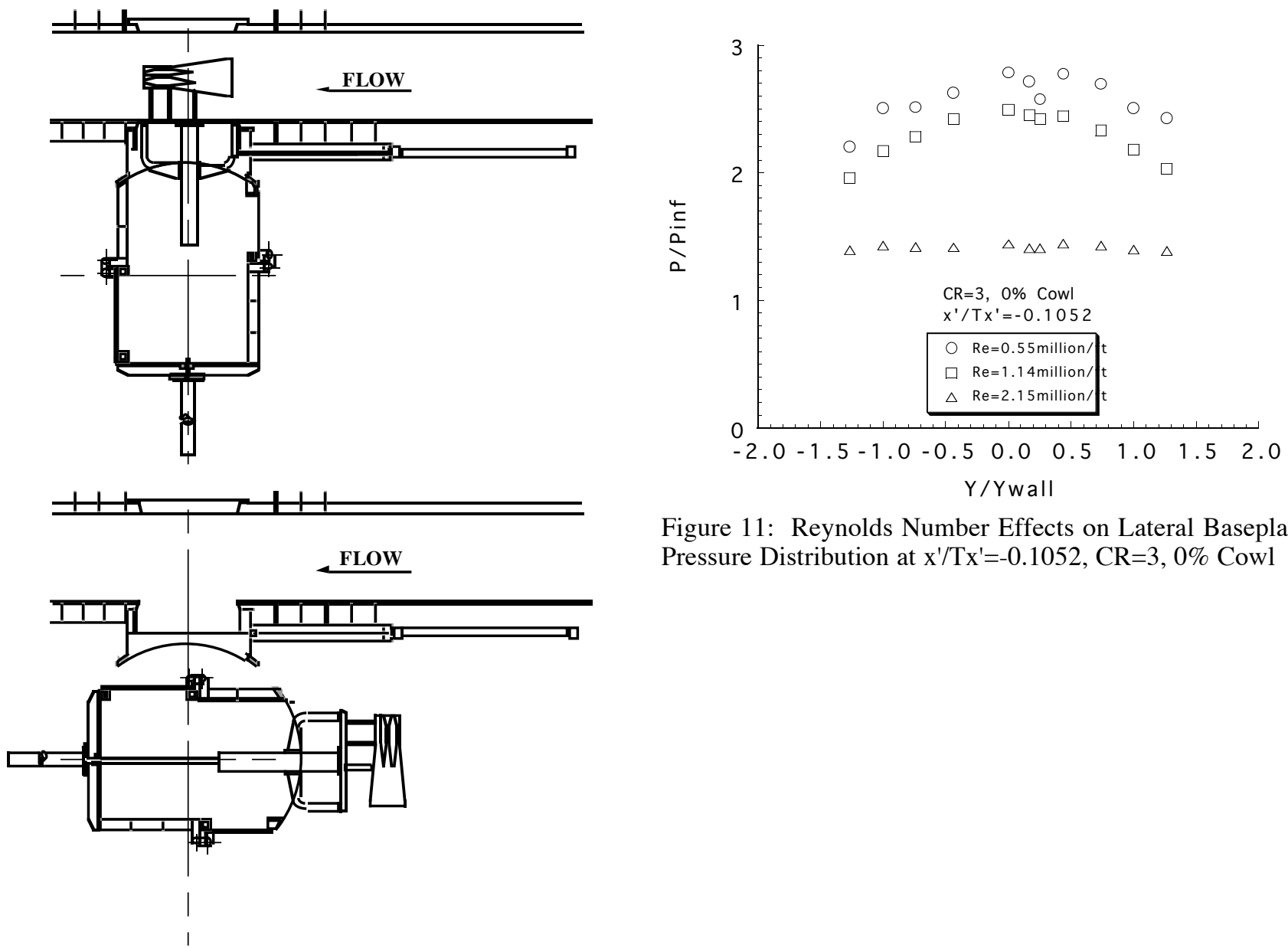

Figure 11: Reynolds Number Effects on Lateral Baseplate Pressure Distribution at $x^{\prime} / T x^{\prime}=-0.1052, C R=3,0 \%$ Cowl

Figure 9: Model Injection Sequence, Showing Model Retracted Prior to Injection, Model Injected into Tunnel, and Model Injected into Work Area 


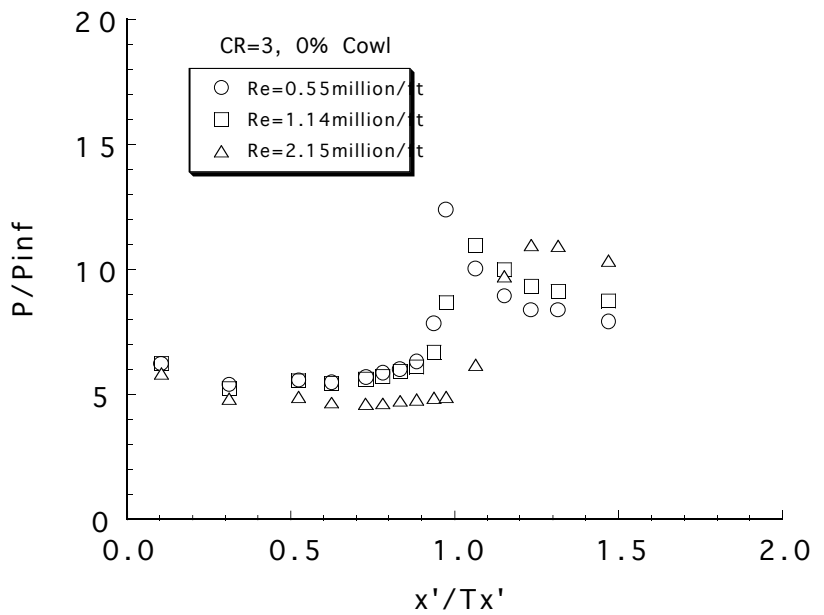

Figure 12: Reynolds Number Effects on Axial Sidewall Centerline Pressure Distribution, $\mathrm{CR}=3,0 \%$ Cowl

Paste Figure Here.

Figure 13: Comparison of Experimental and Computed Baseplate and Sidewall Pressure Distribution for $\mathrm{Re}=2.15 \mathrm{million} / \mathrm{ft}$ and $0.55 \mathrm{million} / \mathrm{ft}$ 


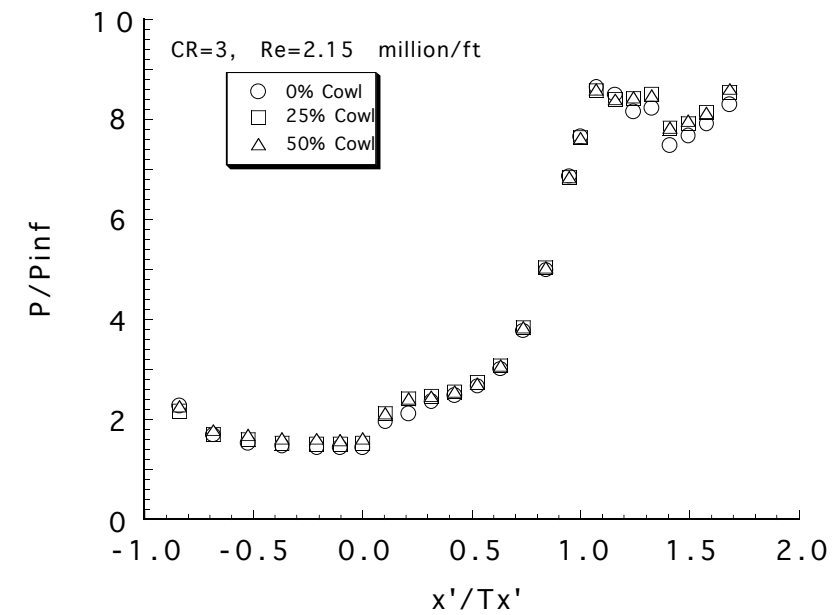

Figure 14: Cowl Position Effects on Baseplate Axial Centerline Pressure Distribution, $\mathrm{CR}=3, \mathrm{Re}=2.15 \mathrm{million} / \mathrm{ft}$

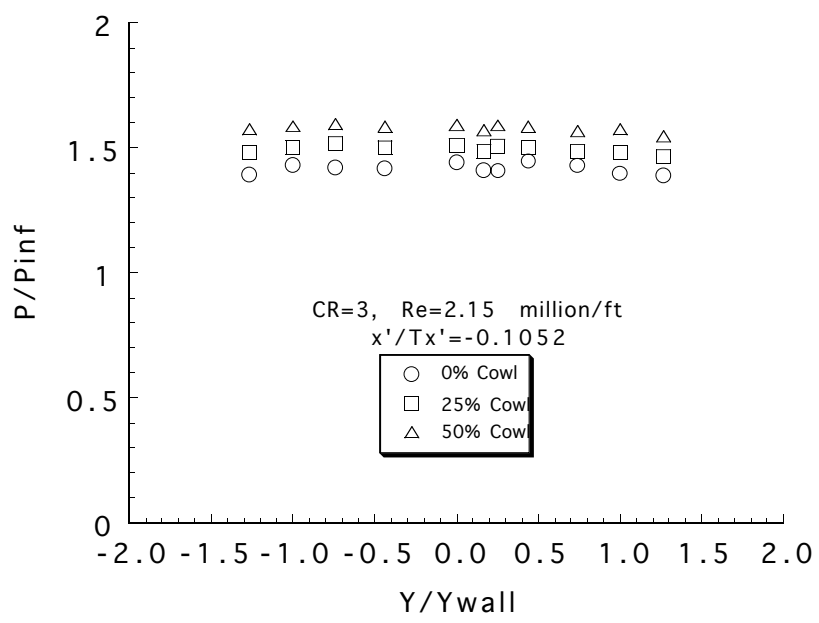

Figure 15: Cowl Position Effects on Lateral Baseplate

Pressure Distribution at $\mathrm{x}^{\prime} / \mathrm{T} \mathrm{x}^{\prime}=-0.1052, \mathrm{CR}=3$, $\mathrm{Re}=2.15 \mathrm{million} / \mathrm{ft}$

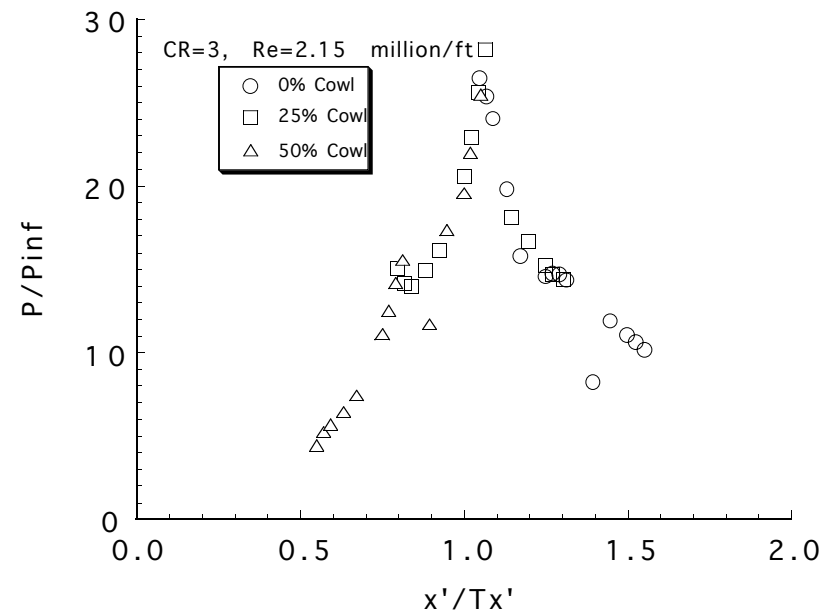

Figure 16: Cowl Position Effects on Axial Cowl Centerline Pressure Distribution, $\mathrm{CR}=3$, $\mathrm{Re}=2.15 \mathrm{million} / \mathrm{ft}$

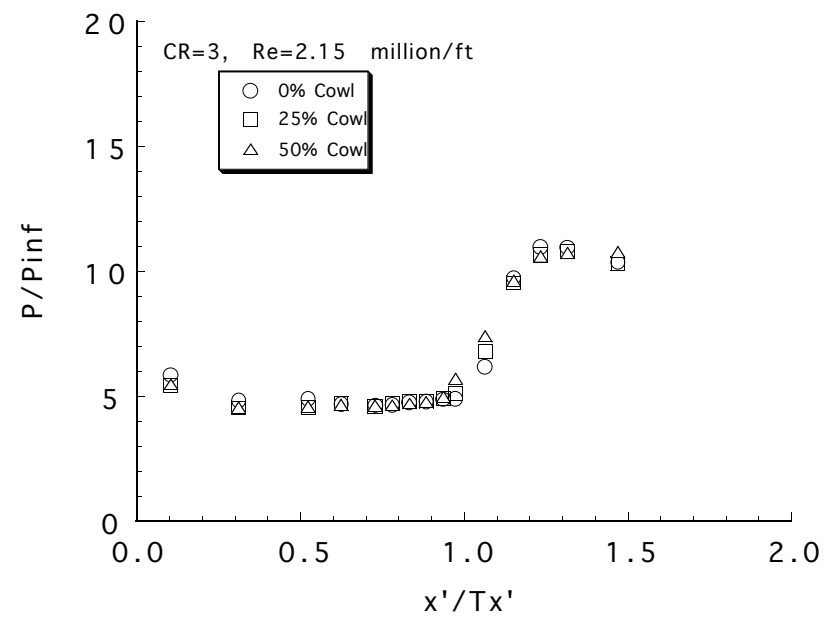

Figure 17: Cowl Position Effects on Axial Sidewall Centerline Pressure Distribution, $\mathrm{CR}=3$, $\mathrm{Re}=2.15 \mathrm{million} / \mathrm{ft}$ 